\title{
MEMÓRIA E HISTÓRIA DE VIDA DE TRÊSS MULHERES E O PAPEL SOCIO-HISTORICO NA CONSTRUÇÃO DA COMUNIDADE TABUA EM GUANAMBI-BA
}

\author{
Alane da Silva Costa Nogueira ${ }^{1}$ \\ Priscila Teixeira da Silva ${ }^{2}$
}

\begin{abstract}
Resumo: Esta pesquisa teve como objetivo compreender o papel de três mulheres, Dona Lú, Dona Mariquinha e Dona Luzia, na formação da comunidade Tabua, no município de Guanambi-BA. Para tanto buscou-se identificar a história da comunidade a partir da memória de moradores identificando assim o nome delas nas falas; o histórico da vida das três mulheres; foi analisado quais costumes e práticas presentes na vida dessas mulheres foram significativos para a constituição da comunidade e se ainda permanecem. A pesquisa trata-se de um estudo qualitativo, pois busca explicar com profundidade o significado e características dos fenômenos. Para coleta de dados fora utilizada a entrevista semiestruturada, a história oral de vida e narrativas orais com uma das senhoras que ainda está viva e com familiares e pessoas da comunidade. no mundo globalizado que vivemos em que os "causos" se tornam menos frequentes, registrar memórias, costumes e histórias contribui para que a cultura local não se perca no tempo. Além do que ao tratar do papel de mulheres na história vai na contramão de uma historiografia machista muito presente no Brasil. O papel das três mulheres para a formação da comunidade se deu através de espaço e convívio social, do seu jeito de viverem, da opinião forte, da força em encarar a vida e o trabalho, da organização das festas, dos costumes presentes na memória de todos. Contudo tais costumes vem se perdendo na comunidade após o falecimento de Dona Lú e Dona Mariquinha, da idade avançada de Dona Luzia e o esvaziamento populacional na comunidade Tabua.
\end{abstract}

Palavras chave: Comunidade. Mulheres. Memória.

Abstract: This research aimed to understand the role of three women, Dona Lú, Dona Mariquinha and Dona Luzia, in the Tabua community formation, in the municipality of Guanambi-BA. In order to do so, we sought to identify the history of the community from the memory of residents, thus identifying their names in the lines; the history of the life of the three women; it was analyzed what customs and practices present in the life of these women were significant for the constitution of the community and if they still remain. The research is a qualitative study, because it seeks to explain in depth the meaning and characteristics of the phenomena. For data collection outside used semistructured interview, oral history of life and oral narratives with one of the ladies who is still alive and with family and people of the community. in the globalized world that we live in that the "causes" become less frequent, registering memories, cus toms and stories contributes so that the local culture does not get lost in the time. Besides that, when

\footnotetext{
1 Graduada em História (UNEB) e discente da pós-graduação Lato Sensu em Metodologia do Ensino de História. E-mail: ianne_@hotmail.com

${ }^{2}$ Doutoranda em Educação e Contemporaneidade ( UNEB). Mestra em Educação do Campo (UFRB). Pedagoga, e. E-mail: priscilats4@hotmail.com
} 
dealing with the role of women in history, it is against the background of a macho historiography very present in Brazil. The role of the three women in the formation of the community was through space and social life, their way of living, their strong opinion, their strength in facing life and work, the organization of parties, customs in the memory of all. However, these customs have been lost in the community after the death of Dona Lú and Dona Mariquinha, of the advanced age of Dona Luzia and the population emptying in the Tabua community.

Keywords: Community. Women. Memory.

\section{INTRUDUÇÃO}

O presente estudo refere-se a uma pesquisa de campo que foi realizada sobre a formação de uma comunidade chamada Tabua, situada a 6 km do Distrito de Mutãs, Guanambi - BA, e a vivência de três senhoras: Luzia, Lú e Mariquinha e o seu papel na formação daquela comunidade.

O estudo parte da perspectiva de considerar a importância dessas mulheres para a formação da comunidade, a figura de mulheres guerreiras que apesar das dificuldades lutaram pela sobrevivência, levando sempre em conta seus costumes, sua cultura perante aquele povo. São mulheres do campo que buscaram a sobrevivência no meio rural, onde a vida é bem simples apesar das dificuldades. Por terem desempenhado um papel marcante na história varias pessoas da comunidade e familiares delas trazem uma bagagem de experiências vividas muito grande. Essas três senhoras com vestimenta diferente do que estava acostumada a ver, saias longas e andavam descalço, adoravam cheirar pó ${ }^{3}$ e não perdoavam se não recebessem a benção, eram as Pebas $^{4}$.

Essas mulheres tem uma relevância muito grande na comunidade e nas comunidades vizinhas, pois elas tiveram um modo de vida diferenciado através de suas crenças e costume que fizeram e fazem história na região. Até o presente momento não há nada cientificamente registrado sobre a identidade e vivências dessas senhoras naquela comunidade, o que traz uma relevância histórica e social desta pesquisa, pois no mundo globalizado que vivemos em que os "causos" se tornam menos frequentes, registrar memórias, costumes e histórias contribui para que a cultura local não se perca no tempo. Além do que ao tratar do papel de mulheres na história vai na contramão de uma historiografia machista muito presente no Brasil.

\footnotetext{
${ }^{3}$ Pó: Folhagem seca torrada e moída.

${ }^{4}$ Apelido dado as três senhoras, cujo motivo não fora identificado na coleta de dados. Embora acredita-se que tal apelido deve-se as características físicas delas, já que o significado do termo peba esta associado a coisa achatada, alongada, comprida.
}

Revista Educação e Ciências Sociais, Salvador, v.1, n.1, 2018. 
Deste modo este estudo tem como objetivo geral compreender o papel de três mulheres para a formação da comunidade Tabua do distrito de Mutãs-Guanambi- BA. Para tanto o trabalho seguiu os seguintes objetivos específicos: Levantar/descrever o histórico da comunidade a partir das memórias de moradores; Identificar a aparição do nome das três senhoras/mulheres nas falas, fazendo o levantamento histórico da vida das mesmas da comunidade; Analisar quais costumes presentes na vida dessas mulheres foram significativos para a constituição da cultura da comunidade e como/se eles ainda permanecem.

\subsection{Metodologia}

Por se tratar de uma pesquisa baseada na história de vida, memória e identidade de três mulheres de uma da comunidade a partir da memória de moradores de uma comunidade rural, fundamentou-se em uma abordagem qualitativa, pois esta segundo Oliveira (2010) busca explicar com profundidade o significado e características obtidas em entrevistas seja ela através de narrativas orais ou semiestruturadas. Deste modo esta abordagem possibilitaria uma investigação mais contextualizada da problemática estudada.

Como instrumentos para coleta de dados foram utilizadas a entrevistas semiestruturada, a história oral de vida e as narrativas orais com uma das senhoras que ainda está viva e com pessoas da comunidade e comunidades vizinhas.

Com o intuito de levantar/descrever o histórico da comunidade a partir de memórias de moradores, utilizaremos as narrativas orais com quatro pessoas da comunidade. A narrativa oral é o momento em que o sujeito relata fatos ocorridos dependendo do seu contexto, segundo Perazzo (2015, p. 121) “A linguagem e, nesse caso, a narrativa oral do sujeito, são possibilidades de armazenamento da memória, por um lado, e de sua expressão e materialização, por outro". Neste estudo a opção pela mesma deu-se por acreditar que esse instrumento condiz melhor com a realidade da comunidade, dos causos, das histórias contadas na porta das casas, então será mais fácil obter a fala espontânea das pessoas. O objetivo foi de identificado à aparição do nome das três senhoras nas falas, fazendo o levantamento histórico-social.

Como uma das senhoras ainda estava viva no período da pesquisa, a mesma foi sujeito da pesquisa. Com ela fora utilizada a história oral, pois suas memórias, sua vida compõe o objeto de estudo desta pesquisa. Segundo Meihy e Holanda (2013, p.18) "história oral é uma prática de apreensão de narrativas feitas através do uso de meios eletrônicos e destinadas a: 
recolher testemunhos, promover analise de processos sociais do presente, e facilitar o conhecimento do meio imediato".

Esse levantamento histórico da vida das três mulheres da comunidade, também requer a utilização de entrevistas semiestruturadas com membros da família e vizinhos próximos. A entrevista semiestruturada trata-se o sujeito com perguntas fechadas e abertas, o participante pode acrescentar ideias de perguntas criada no momentos o sujeito pesquisado fica livre para responder e agregar conhecimento (MINAYO, 2016). Foram entrevistas feitas com pessoas que fizeram parte da vida dessas mulheres e que autorizaram usar os seus nomes neste trabalho de monografia.

Todas as informações foram gravadas com autorização dos sujeitos e posteriormente transcritas, que também pediram para que fossem utilizados seus nomes verdadeiros. Durante a pesquisa surgiu a necessidade de registro fotográfico e da utilização de fotos apresentadas pelos participantes da pesquisa, o que fora utilizado neste trabalho com a autorização de Dona Luzia e dos familiares das demais senhoras. Para análise dos dados foi utilizada a análise de conteúdo, definida por Bardin (1979, p.42) como:

É um conjunto de técnicas de análise da comunicação visando obter, por procedimentos sistemáticos e objetivos de descrição do conteúdo das mensagens, indicadores (qualitativas ou não) que permitem a interferência de conhecimento relativos às condições de produção /recepção (variáveis inferidas) destas mensagem.

Com base nos dados coletados foram analisados quais costumes presentes na vida dessas mulheres foram significativos na constituição da cultura da comunidade e se elas ainda permanecem, identificando assim o papel dessas três mulheres para a formação da comunidade Tabua.

\section{A REPRESENTAÇÃO SOCIAL, HISTÓRIA E MEMÓRIA}

A representação social das três mulheres negras para a formação da comunidade Tabua é que me instigou o desejo de fazer a pesquisa sobre a vida e vivência dessas senhoras naquele local, lembrando que duas delas estão in memória. Deste modo o estudo fundamentou-se na relação de identidade, memória e história vida, essa relação foi observada com propriedade por Proença, ao propor essa abordagem afirma:

Revista Educação e Ciências Sociais, Salvador, v.1, n.1, 2018 
Se o conhecimento histórico é indispensável na construção de identidade, sob o ponto de vista pedagógico- didático é importante ter em conta o tratamento da memória longa das populações que nos permite explicar diferentes ritmos de evolução, o estudo das memórias coletivas de diferentes grupos que pertença, a pesquisa das memórias locais nos diferentes âmbitos de duração, a reabilitação da memória do trabalho, numa sociedade ocidental que sempre ignorou ou desprezou o trabalho manual, e a memória do tempo curto de acontecimentos, que caracteriza o estudo da história do século XX. (PROENÇA, 1990, p.24).

A autora deixa bem clara a importância da memória da identidade e que é pela memória que se chega à história local e social. Isso é o que vai ser observado e identificado durante a pesquisa. A memória não pode ser misturada com história, as duas caminham uma do lado da outra, porém cada uma com a sua finalidade, ambas tem que ser trabalhadas e confrontadas. A memória é a relação coletiva que uma comunidade tem a respeito do seu passado, o relacionamento do sujeito de hoje com o passado; e a história é junção e o acumulo dessas memórias. Para Le Goff (1988, p.109) a história “consiste na escolha e construção de um objeto, operação de que dar-se a partir da invocação de lembranças".

A pesquisa foi realizada com base no lugar e nas vivências das três senhoras na comunidade. O geógrafo Milton Santos apresenta em várias obras o pensamento sobre o espaço geográfico e as sua contribuição para a formação do lugar, numa perspectiva histórica. Segundo ele pode-se ter atribuição/função diferentes ao mesmo lugar:

O lugar é um conjunto de objetos que tem autonomia de existência pelas coisas que o formam [...] mas que não têm autonomia de significação, pois todos os dias novas funções substituem as antigas, novas funções se impõem e se exercem (SANTOS, 1991, p. 52).

Cada lugar é visto por cada sujeito com um olhar diferente, e é lembrado através de memórias com objeto de estudo diferenciado, cada um tem a sua opinião formada e suas lembranças também, por isso é relevante fazer pesquisas com um olhar crítico da realidade. Os moradores da comunidade Tabua, do ponto de vista histórico, trazem uma bagagem de experiências e identidade diferenciada das demais comunidades próximas, por isso é interessante fazer pesquisa não só com os moradores de lá, mas também com os de comunidades próximas sobre a representação histórica daquelas três senhoras da comunidade Tabua. Sabendo que a memória e o lugar são abordados de acordo o tempo pelo qual a memória está ligada. 
Ao estudar o sujeito do campo partindo da história de vida e memória é interessante salientar os costumes presentes na vida, no caso, dessas mulheres e sua importância na constituição da cultura daquela comunidade, e se ainda permanecem. Assim a memória individual e coletiva dos sujeitos pesquisados são é o corpo vivo no processo de se relacionar o passado é a memória social e trazer história partindo dessas memórias.

\subsection{Representação social: um conceito, uma abordagem}

Representação social estabelece-se como configuração de informação experiente, esta monografia busca colocar a investida da Psicologia Social dentre as demais correntezas que se chegam sobre as demandas e informação do conhecimento. As representações sociais, segundo definição clássica apresentada por Jodelet (1985) são "estudos de informação experiente dirigidas para a concessão e para a captação do todo igualitário, a qual o local que sujeito está inserido

Para Bittencourt (2009 p. 236) "a representação social é entendida como uma modalidade particular de conhecimento". O conhecimento depende do local em que você está inserido e como conviveu nele, refletindo basicamente na transversalidade das representações sociais, não há confusão de que, permanecendo localizada na interconexão dos acontecimentos pessoal e grupal, estas ciências. E estudar a identidade de um povo através de suas crenças e costumes; é a história de vida de um povo de acordo a sua região seja no modo de falar, se comportar perante uma comunidade.

Os moradores da comunidade Tabua tem suas experiências de vida muito diferentes das demais comunidades vizinhas. A história de vida é a história do cotidiano e do seu meio social, cada um traz sua cultura através de familiares na construção da memória. Embora caiba salientar que nem todas as pessoas valorizam esse passado.

\subsection{Memória e constituição histórica}

Falar de memória é relembrar algo que fez parte do convívio social, seja acontecido a pouco ou muito tempo à importância a qual o sujeito dá a verdadeira veracidade dos fatos e acontecimento de acordo a sua maneira de pensar e de questionar com uma visão ampla da realidade. Segundo Le Golff (2003 p. 387) “a memória, como propriedade de conservar certas 
informações, remetemos em primeiro lugar a um conjunto de funções psíquicas, graças os quais o homem pode atualizar impressões ou informações passadas, ou que eles representa como passadas".

A memória é relembrar um passado, é um instrumento que tem um grande poder de memorização, é o que conduz o ser humano na sua vida tanto pessoal quanto social. Para Bosi (2003 p.15) "é um instrumento precioso se desejamos constituir a crônica do quotidiano. Mas ela sempre corre risco de cair numa 'ideologização' da história do quotidiano, como se está fosse o acervo oculto da história política hegemônica".

A memória através do uso da constituição histórica corre o risco de entrar para o esquecimento, pois no mundo globalizado de grandes tecnologias, os sujeitos não sentam mais com as pessoas mais velhas para ouvir os causos do passado, por isso é de fundamental importância que os novos historiadores tenham esse papel de resgatar essas memórias e mostrar que o passado também faz parte do convívio social do ser humano. E analisa-las de forma analítica já que com as memórias vem as indagações do que é real e o que místico, pois é a história contada de forma empírica, do jeito de cada um se expressar.

A história da comunidade Tabua não é diferente, as pessoas da comunidade tiveram uma vivência delas mesmo e por isso trazem seus enraizamentos através de suas memórias. Para Bosy (op. Cit. p.16) "a memória se enraíza no concreto, no espaço, gesto, imagem e objeto. A história se liga apenas às continuidades temporais, as evoluções e as relações entre as coisas". É que a memória está em constante evolução é um corpo presente partindo de passado vivido, seja ela individual ou coletiva. Bosy (op. Cit. p.17) complementa afirmando que "essa força da memória coletiva, trabalhada pela ideologia, sobre a memória individual do recordar, o que ocorreu mesmo quando este participou e testemunhou os fatos e poderia, portanto nos dar uma descrição diferenciada e viva".

A memória é cheia de pegadinhas, a cada causo contato sempre aparece coisas novas, ou o esquecimento. Contudo é esse exercício de resgate que se chega à restauração da memória partindo do interesse pessoal e vivenciado, pois pode acontecer uma falha com a reposição constante de dados, no que chamamos de computador humano.

\subsubsection{Memória de velhos}


"Memória de velho" é a expressão não muito aceita socialmente, constantemente taxada como preconceituosa pela sociedade que usa outras expressões que delimitam essa ideia de "terceira idade". Claro que a memória de velho nunca se envelhece é o conjunto de lembranças trazida de um passado e presente, onde é dirigido por um sujeito vivido ou vivenciado, geralmente essas lembranças são coletivas através de rodas de conversas.

Bosi (1994) lembra a importância do velho nos dias de hoje, incluído do meio social o velho perdeu o desejo e a importância de ser ouvido, deixando de lado o ato de narrar e ser narrado, os jovens perderam a paciência de ouvir. É interessante salientar que os velhos de hoje, foram os jovens de antigamente e que os jovens de hoje vão ser os velhos futuramente, isso é fato, a vida está em constante evolução. Boa parte dos acontecimentos passam desapercebidos pelos adolescente, eles não dão a verdadeira valorização do que poderia ser dado ao momento.

Durante a coleta de dados, em uma conversa com Maria, uma das filha de Dona Luzia, quando a perguntei sobre como estava dona Luzia e ela disse que dona Luzia não sabia de quase nada, está muito esquecida e a cabeça é ruim. Chegando ao local da casa de Dona Luzia começamos a conversar, sobre como foi a formação da fazenda Tabua e quem era os moradores e percebi que ela sabia de muitas coisas, relatava fatos como se fosse o momento do acontecido. E ai seguiu a conversa entre eu, Dona Luzia e Maria, uma conversa prazerosa onde percebi que Dona Luzia só estava um pouco surda, ai vem a ideia da falta de paciência com mais velhos, de achar que não tem capacidade de dar respostas.

A memória dos velhos não é problema, o problema está nas pessoas, no meio social que não acreditam na capacidade da memória de um velho. A memória de velho tem posição hierárquica, é lembrar da memória através de relatar fatos. O tempo narrado foi o momento vivido e a identidade diferenciada do meio social, é a grande importância do texto, é lembrar de uma trajetória de vida na velhice, é a recontar um passado a um sujeito no presente.

Segundo Le Goff (2013 p.393) “A memória coletiva parece, portanto, funcionar nestas sociedades segundo uma reconstrução generativa e não segundo uma memorização mecânica". Isso é devido à conversa, a troca de ideias que se chega a uma realidade, que se lembra de algumas coisas e se esquece de outras. São nas conversas orais com amigos, familiares que se chega a verdadeira veracidade dos fatos, nesta linha e que Bosi (2003, p. 53) salienta que "A memória é, sim, um trabalho sobre o tempo, mas sobre o tempo vivido, conotado pela cultura e pelo individuo". E através dessas conversas coletivas que se chega as memórias contadas e vividas dos sujeitos e de quem eles recordam. Para Pinto, Gomes e Silva (2008, p.41.42): 
A memória é um refazer das experiências passadas exigindo com isso devotamento e trabalho por parte daqueles que se voltam às lembranças de um tempo longínquo e que, com ajuda dos materiais presentes em seu entorno atual, esforçam-se em um trabalho consciente de rememoração.

Nesta perspectiva é que através das lembranças de um passado, através da memória, é que se analisa o presente, sendo parte fundamental e social na vida do ser humano. Segundo Bosi (op. Cit.) a memória é a preservação do ser humano e o comando entre a ideia e o ser social. Neste estudo os moradores foram sujeitos da pesquisa, revelando o convívio social e os costumes como a maior parte das lembranças de velhos contadas por pessoas que tiveram um conviveu na comunidade.

Bosi (1994, p. 38) afirma que "fomos ao mesmo tempo sujeito e objeto. Sujeito enquanto indagávamos, procurávamos saber. Objeto enquanto ouvíamos, registrávamos, sendo como que um instrumento de receber e transmitir suas lembranças". Nesta condição que me coloquei como pesquisadora neste estudo, e reconheço a perca que se tem de um todo maior ao se registrar o narrado, como base num objetivo pré-definido, como corrobora Bosi (2003, p. 44), ao dizer que a narrativa que ignora a sedimentação do discurso escrito é temporal e não espacializadora, modalidade própria dessa visão imediata do passado que a rigor e também intuição de um presente desvendado. Isso são as fases da memória, porque é com o tempo que é entendido os seguimentos da memória através de pensamentos e do discurso coletivo.

\section{MEMÓRIA E HISTÓRIA DE VIDA DE TRÊS MULHERES NEGRAS DA COMUNIDADE TABUA, GUANAMBI-BA: Luzia, Lú e Mariquinha}

A história faz parte do cotidiano, através de seu espaço de conviveu e juntamente com ele vem o pensar e o estudo da memória através de seus pensamento revivendo e a um passado que pode ser distante e pode ter acontecido a pouco tempo tudo faz parte da memória.

Ao se referir à palavra memória logo associamos a relembrar algo do passado e a histórias contadas pelos avós, pais... Neste trabalho não é diferente, por se tratar da história de vida de três mulheres de uma comunidade, seus costumes, e o papel social delas para a formação da comunidade.

\subsection{A comunidade de Tabua}


A comunidade Tabua está localizada a seis quilometro do distrito de Mutans da cidade de Guanambi -BA, próximo a "estrada de dentro" que liga o distrito a cidade de Candiba, conforme ilustra o mapa 1.

Mapa 1: Localização da comunidade Tabua

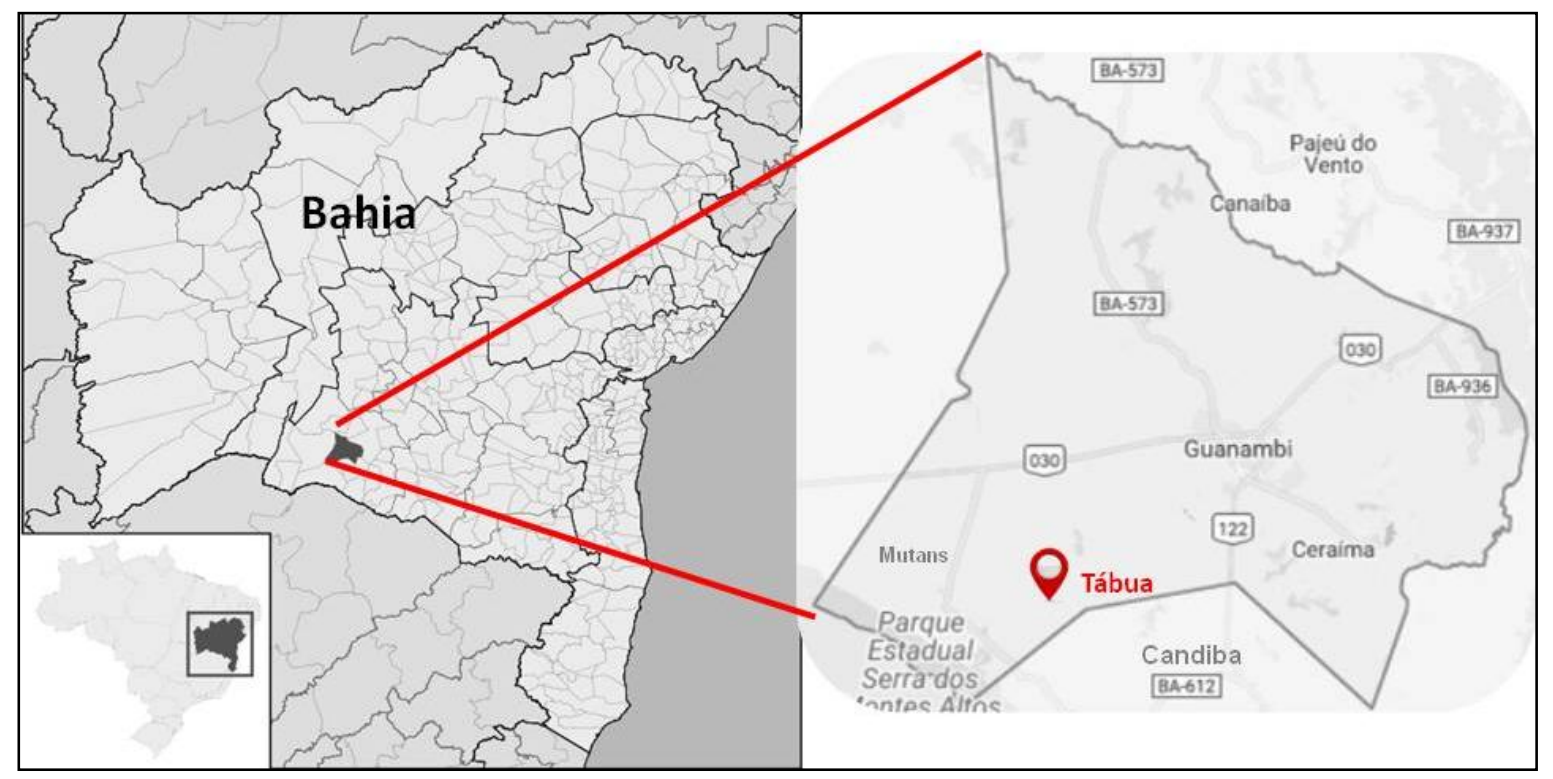

Fonte: construído pelas pesquisadoras com base no Google mapas.

É uma comunidade rodeada de mata rasteira e com algumas árvores grandes. Por ser uma comunidade pequena e por características de seu povoamento todos moradores, são parentes e a comunidade constitui-se basicamente de pessoas negras.

Segundo os moradores, o nome da comunidade vem da abundancia de uma erva denominada popularmente como taboa ${ }^{5}$ ao redor da lagoa existente na comunidade. Passava as águas, chovia novamente e ela não secava, com o passar do tempo à lagoa ficou praticamente aterrada devido às areias que as enxurradas traziam com isso a taboa tomou conta da lagoa. Atualmente a lagoa se encontra com um pouco da erva, capim nativo e quando chove só junta um pouco de água e logo seca, os moradores afirmam que a comunidade não manda a máquina limpar a lagoa, porque não tem condições financeiras.

Dona Luzia, a única ainda viva das mulheres deste estudo, conta que ela chegou na comunidade aos sete anos de idade juntamente com sua mãe e seu pai, e que por lá já moravam seus avós, Sr. Antônio e Dona Sebastiana e seus tios Leocádio, Silistrino, Amasar, Dora, Silivera, Maria Lú e Mariquinha que era sua tia emprestada.

\footnotetext{
${ }^{5}$ Nome científico Typha Dominguensis Pers. 
Figura 1: Casa antiga de Dona Luzia e a casa atual.
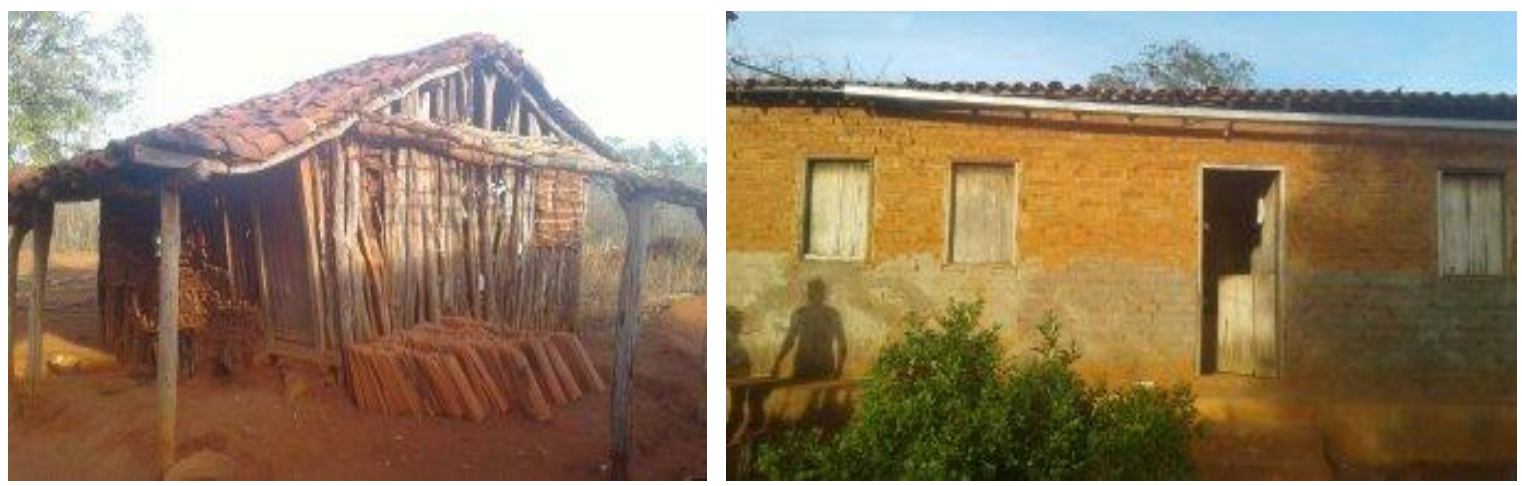

Fonte: Fotos tiradas pelas pesquisadoras.

A casa de Dona Lú foi derrubada, por terceiros, para retirar a madeira, o interessante é que eles não retiraram nada que tinham dentro da casa, derrubaram com tudo dentro. A filha de Dona Luzia relatou que o pessoal roubou tudo o que a tia dela tinha lembra das colchas bonitas e afirma que só deixaram os potes.

\section{Figura 2: Casa de Dona Lú após a demolição.}

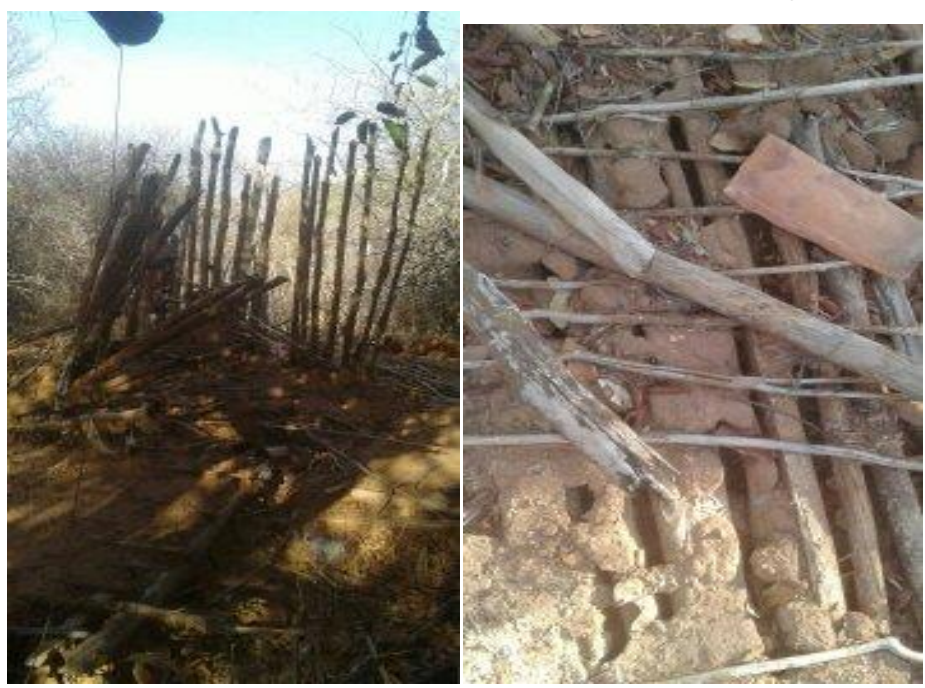

Fonte: Fotos tiradas pelas pesquisadoras.

Dona Lú costumava fazer sua comida em baixo dos pés de umbuzeiros, colocava três pedras, a lenha, acendia o fogo e colocava a panela de barro onde fazia as comidas. Ela sempre vinha em Mutãs no sábado comprar as carnes, quando não matava o capado (porco) lá mesmo, 
temperava e cozinhava tudo de uma única vez, eu mesma já provei sua comida e posso dizer que nunca comi uma carne tão gostosa em toda minha vida.

\section{Figura 3: Terreiro da casa de Dona Lú.}

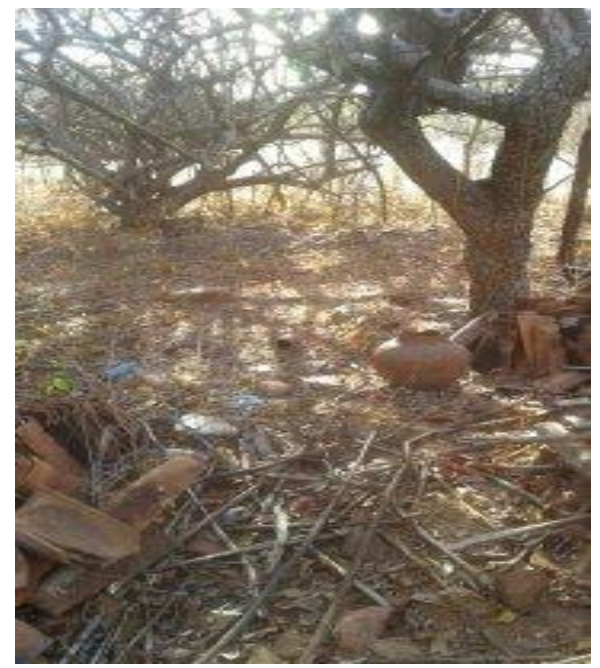

Fonte: Foto tirada pelas pesquisadoras.

Ao lado de sua casa passava-se o córrego que deságua na lagoa da Tabua, em tempos de chuva Dona Lú não poderia ficar em sua casa porque o córrego transbordava e poderia invadir a sua casa.

Já Dona Mariquinha por morar numa casa caracterizada pela secretária Municipal de Ação Social como sem condições de moradia, ganhou uma casa construída pela Prefeitura Municipal de Guanambi.

Figura 4: Casa antiga de Dona Mariquinha e a construída pela Prefeitura
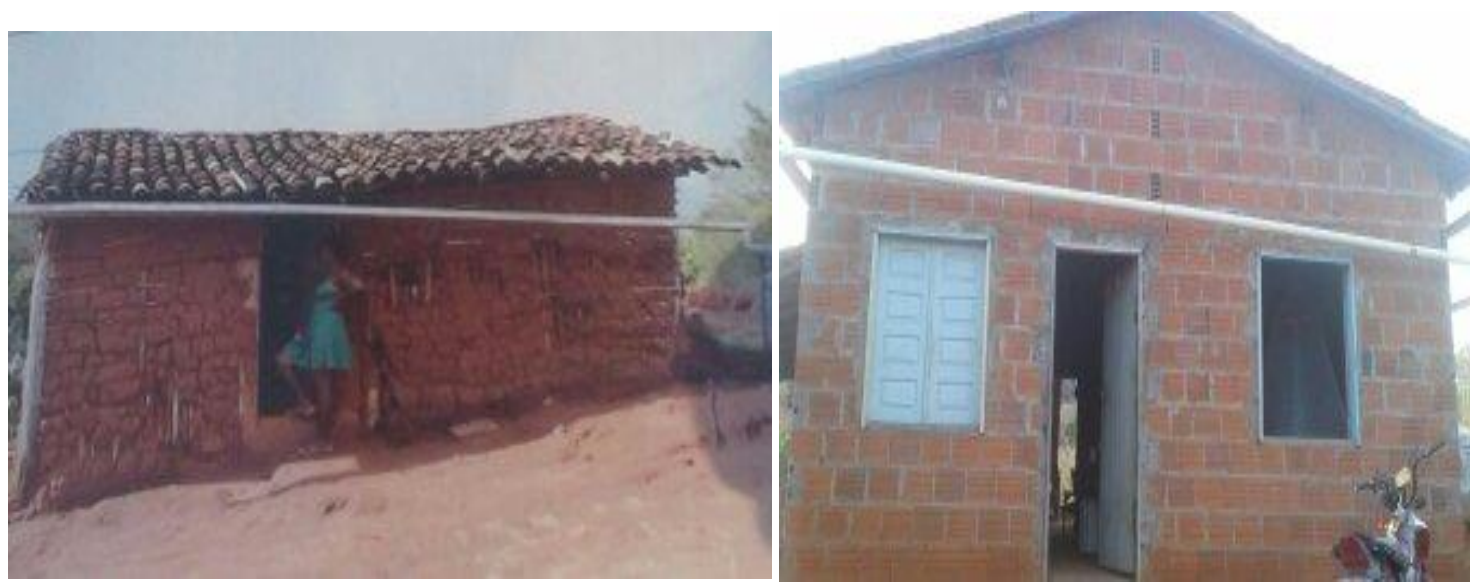

Fonte: Foto da esquerda encontrada de arquivos municipais e a da direita retirada pelas pesquisadoras.

Revista Educação e Ciências Sociais, Salvador, v.1, n.1, 2018. 
É notório as condições simples de vida dessas mulheres, morando grande parte de suas vidas em casas feitas de taipa ${ }^{6}$, recorrendo a bicas para captação da chuva para ter acesso a água. Segundo o senhor Rosalvo, entrevisto durante a pesquisa, a família deles plantava feijão, cana de açúcar, batata, abóbora, criava porcos e quando a lagoa era cheia Dona na época de chuva de acordo com Dona Caetana, também entrevistada, eles tinham acesso a peixes.

\subsection{Três mulheres e uma comunidade}

Nesse contexto de simplicidade se inicia o vínculo dessas três mulheres: Dona Luzia a sobrinha de Dona Lú e Dona Mariquinha. A vida as levou por um caminho trilhado juntas, mas também marcados pela solidão, por suas percas familiares rápidas.

Dona Luzia: Tia Lú (in memória) era irmã da minha mãe é casada com tio Celso Lino,não tiveram filhos e depois separam, tio foi embora. E tia Mariquinha, tia emprestada, era casada com Silistrino, também não tiveram filhos naquele tempo não tinha tratamento, não fazia exame, e viveram junto até o momento que Deus, quis porque tio Silistrino morreu. (história oral, 2017)

Dona Lú e Dona Mariquinha se tornaram mulheres solteiras, pela separação ou pela morte, e sem filhos. Já Dona Luzia ainda teve uma filha, mas também se separou logo do marido em circunstâncias difíceis, como relata a mesma:

Dona Luzia: Eu cansei com vinte e cinco anos com uma infricidade ${ }^{7}$ que tem o nome... Acho que ainda é vivo, Osvaldino, tive minha filha Maria da Solidade mas com quinze dias de nascida, eu ainda estava de resguardo ele quis embora juntou as coisas, pois nas costas e foi embora. Passou um tempo ai ele voltou ai eu lhe falei que tinha ido e não queria saber dele mais não, ai tio Silistrino pegou a cartucheira... gritei para tio não fazer besteira, falei ir embora, peguei a coberta que ele tinha deixado para minha filha e mandei levar embora ele saiu no meio do mato lá na frente escutei um tiro essa foi a última vez que eu o vi. Criei minha filha praticamente sozinha ela casou me deu muitos netos, da minha família dos mais velhos só tem eu os outros morreram. (história oral, 2017)

\footnotetext{
${ }^{6}$ Sistema de construção que usa barro molhado para fechar paredes

${ }^{7}$ Infelicidade: sentimento associado ao homem que trouxe várias decepções na vida dela. 
Três mulheres negras, pobres e sozinhas que tiveram que enfrentar a vida dura da roça, mas que eram conhecidas e respeitadas por toda a comunidade, como pode ser observado nos relatos do senhor Rosalvo e sua esposa Caetana, ao falar da família de Dona Luzia:

Rosalvo: Conheci Luzia que ela é prima de Caetana, sempre ia lá, sempre matava o capado (porco) eu era o matador, eles matavam para comer e sempre me dava um pedaço da carne, inclusive foi no matando um capado que começou a discussão de Celso Lino, esposo de Dona Lú, eles brigaram ai ele foi embora, nunca mais voltou. Eu vir toda discussão. (entrevista, 2017)

Caetana: Elas eram pessoas de opinião o que falavam estava falado e não tia medo não. (entrevista, 2017)

A história dessas mulheres perante aquela comunidade é associada a ideia de mulheres guerreira, e que tiveram um grande papel histórico naquela comunidade.

A filha de Dona Luzia (Maria) tinha a foto de Dona Luzia e Dona Lu, tiradas em Bom Jesus da Lapa (figura 7), mas não conseguimos nenhuma foto mais próxima, além da retirada da casa, de Dona Mariquinha, pois segundo Maria ela não gostava de ser fotografada.

Figura 5: Dona Luzia e Dona Lú em Bom Jesus da Lapa.
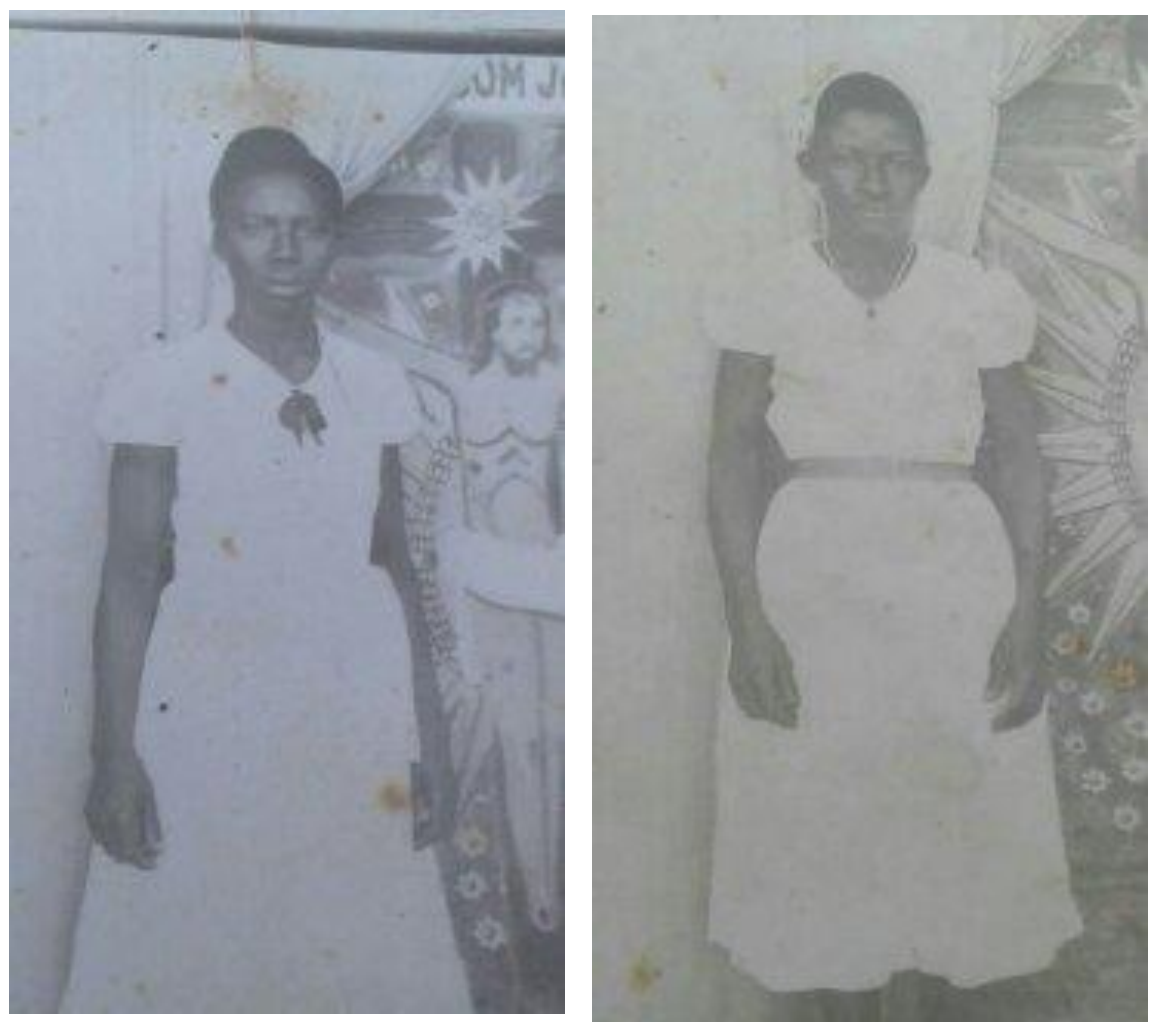

Fonte: arquivo pessoal dos entrevistados. 
Em entrevista feita com Maria e uma antiga vizinha delas, que hoje mora no distrito de Mutãs, Dona Ló fiz perguntas para ambas sobre a vida das três senhoras:

Pesquisadora: Ao falar de Três mulheres da fazenda Tabua o que vocês podem dizer?

Maria: Os homens daqui morreram tudo, falo dos mais velhos, então, só ficou elas para fazer tudo, capinavam, tiram madeira, fazia serviço de homem.

Dona Ló: Eram mulheres boas, tenho muitas saudades daqueles tempos, em que eu ia lá buscar cana de açúcar, batata doce, mangas, a casa delas eram de enchimentos.

Pesquisadora: O que vocês podem relatar sobre Dona Lú, Luzia e Mariquinha?

Maria: Tia Lú morava na casa de enchimento, no meio da mata, ficava lá só durante o dia a noite dormia na casa de mãe (Dona Luzia) isso depois que tia Mariquinha morreu. Mãe morou na casa de enchimento quando chovia parecia que estava no terreiro com tanta água dentro de casa, nesta casa ele viveu desde seus sete anos. Eu nasci, meus filhos do primeiro casamento nasceu e moraram por muito tempo, depois as pessoas da comunidade fizeram uma nova casa para ela. Tecia panos, fazia bordados, rechelie, tricô... e tia Mariquinha Morava numa casa também de enchimento, adoravam olhar os pés de manga para ninguém arranca-la, só podia chupar a que caísse do chão, não teve filho, era uma pessoa de muita opinião.

Dona Ló: Sempre eu ia lá, ela colocava três pedras e lenha e fazia o fogão onde cozinhava e fazia café, com lata de óleo colocava no fogo fazia o café e deixava o tempo todo no fogo, quando chegava ela me dava o café e rapadura. Luzia é benzedeira, sempre ia em sua casa, fazia sempre bolos para ela para as festas de São João, também ficava muito tempo lá porque seu Pedro Donato patrão meu arrendava uma parte do terreno para criar gado, ai o gado bebia na lagoa da Tabua, tirava água de lata para colocar nos cocho do gado, pois tinha muita taboa, o gado não tinha como bebe lá. Era uma fartura das coisas na época da lagoa, da lagoa, quero voltar lá um dia para ver Luzia, assim que meu filho puder me levar, e Mariquinha não tive costume com ela não.

Segundo os relatos das três Dona Luzia era a mais sociável, talvez por ser mais nova ou por ser benzedeira tinha um contato maior com as pessoas. Dona mariquinha era muito fechada, ela sempre olhava os pés de manga, não conhecia dinheiro e quando vinha para Mutãs vinha ela e Dona Lú sentada no fundo da carroça porque tinha medo de vir de cavalo. Sempre andava as três mulheres quando vivas, hoje só ficou Dona Luzia e elas gostavam de cheirar muito pó e não perdoavam se não recebessem a benção.

Dona Caetana relatou que também participou da quinzena para a construção da estrada juntamente com Dona Lú, Luzia e Mariquinha. Essas mulheres guerreiras também fizeram parte da construção manualmente da estrada que liga Mutãs a Candiba. Trabalhava-se numa quinzena 
onde só era quinze dias ao mês, as dificuldades eram muitas, então para ajudar a família as mulheres trabalhavam.

Figura 6: Pessoas trabalhando na quinzena.
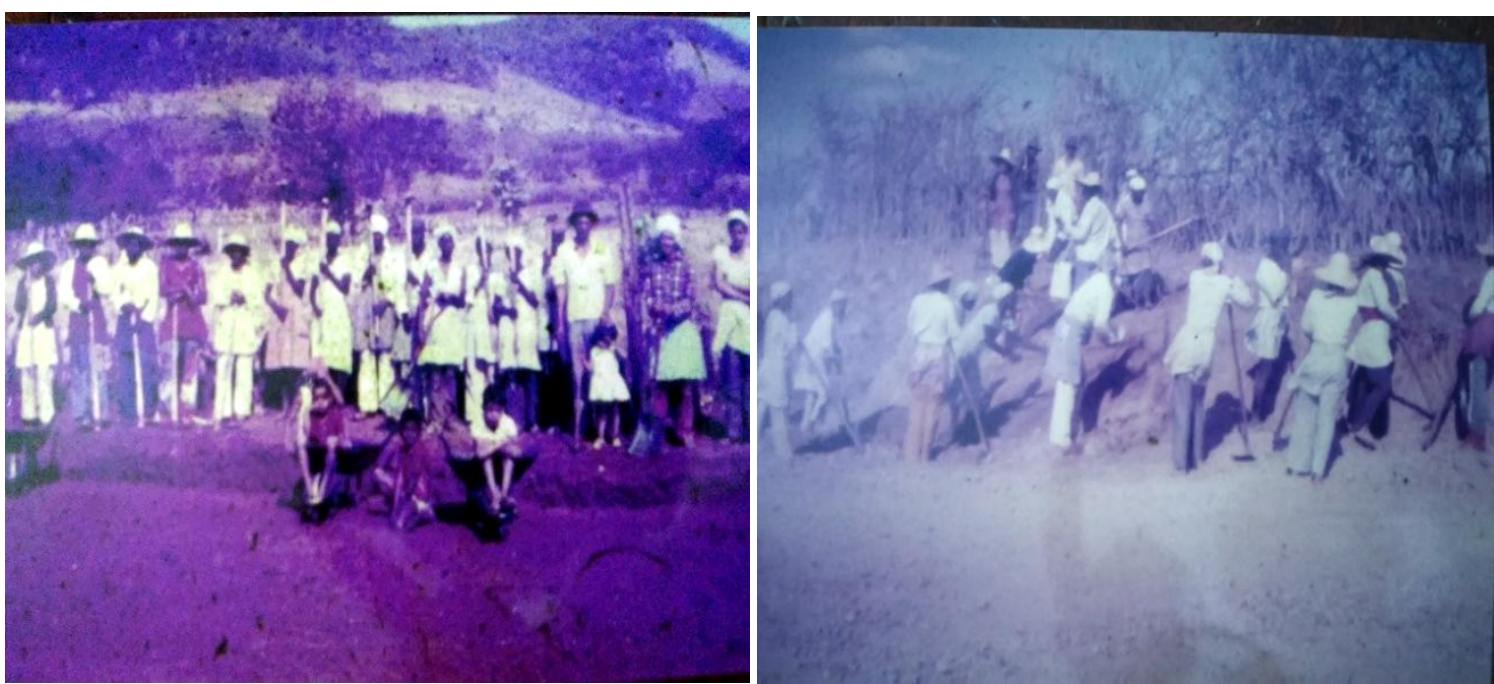

Fonte: arquivo pessoal de Dona Caetana.

É notorio perceber a impolgação de Dona Caetana ao relatar esse fato, pegou a foto e me mostrou estava dentro de um binóculo, foi feita a restauração da foto, mostrando o orgulho em ter feito parte dessa história. E também a força dessas mulheres ao desempenharem servisos braçais pesados em prol da melhoria da mobilidade da comunidade.

\subsection{Três mulheres e seus costumes na cultura da comunidade: memórias...}

A comunidade de Tabua é um lugar de muita interação, esta localizada no alto de um morro de onde é possível ver as comunidades próximas como Barreiro, Espinheiro, Olho D' Água. Essas mulheres eram muito conhecidas por promover festas na comunidade Tabua, era de tradição a festa de Santa Luzia, no dia 12 de dezembro, onde tocava muito tambor, pandeiro, batia pilão e geralmente acontecia em cima do morro, eram mulheres muito animadas. 
Elas também eram convidadas para tocar nas comunidades vizinhas. Com o passar do tempo tudo foi acabando, a lagoa secou, as plantações morreram, exceto uns pés de manga, os peixes acabaram. A água da comunidade hoje vem de um poço artesiano de uma comunidade próxima, Barreiro, onde a água só dá mesmo para o consumo de casa. Hoje na comunidade tem poucos moradores, as pessoas mais novas saíram para trabalhar, só tem Maria da Solidade, Jucilene, Genivaldo, Dona Luzia, e um primo dela.

\section{Figura 7: Foto de Dona Luzia e sua Filha Maria}

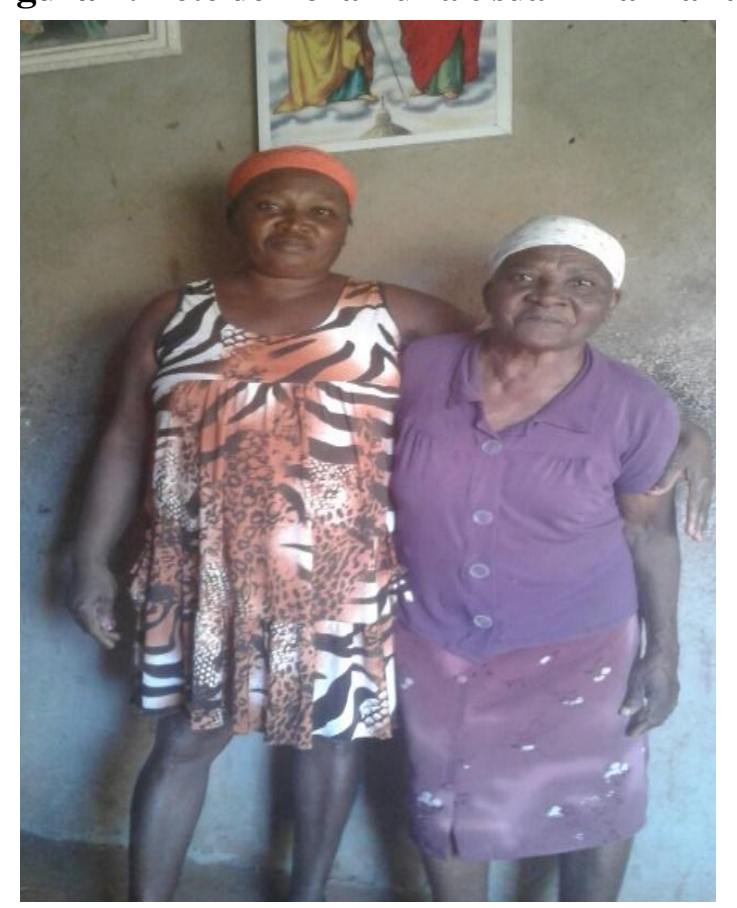

Fonte: Foto tirada pela pesquisadora.

Dona Luzia está com setenta e sete anos, com alguns problemas de saúde, mora com sua neta Jucilene e seu filho e esposo. A filha de Dona Luzia mora em outra casa próximo, casou-se novamente e teve uma filha com esse outro marido que é seu parente distante. As festas acabaram deixando para trás recordações de um passado que ficou na memória de todas as pessoas que conheceram e participaram da vida dessas mulheres.

\section{CONSIDERAÇÕES FINAIS}

Este trabalho teve como tema, identidade, memória e história de vida seguindo como objetivo geral compreender o papel de três mulheres para a formação da comunidade Tabua do distrito de Mutãs, Guanambi-BA, tendo como foco, levantar e descrever a história da comunidade Tabua, partindo da memória moradores; identificando a citação do nome das senhoras nas falas; fazendo o levantamento histórico da vida das três mulheres na comunidade; 
analisando seus costumes presente na vida mulheres foram significativos para a constituição da cultura da comunidade e se ainda permanecem.

O conceito e de representações sociais, memória e constituição histórica no cenário da memória de velhos, mostra a importância dos velhos e a junção das memórias trazendo o debate sobre memória, constituição histórica e identidade.

A comunidade Tabua é a memória e história de vida de dessas três mulheres negras, pois o papel das mesmas na constituição da comunidade é evidente . Assim este estudo trata-se do registro da memória de Dona Luzia, sua filha Maria, moradores, pessoas de comunidades vizinhas e parentes que as conheceram e fizeram parte da historia das três mulheres pesquisadas. Além disso, traz a cultura e costumes dessas mulheres na comunidade refletindo se eles perduram até os dias atuais.

Dona Luzia narrou fatos e vivências daquele momento, como era a vida ali com seus pais, avós e tios era filha única e seus tios não tiveram filho os mais velhos morreram só restava ela. Vive na comunidade desde os sete anos de idade e está até hoje lá aos 77 anos. Teve uma filha Maria da Solidade, que lhe deu seis netos, dois deles ainda permanecem na comunidade, os outros casaram e se mudaram do local.

Também foram relatados das festas divertidas ali existentes antigamente, como eram as festas de Santa Luzia e que recebia visitantes de todas as comunidades vizinhas. Analisando os dados coletados percebe-se que as festas ali acabaram, por conta do falecimento das pessoas ali existentes, todo animação acabou depois que morreu Dona Mariquinha e posteriormente dona Lú. Com isso mudou todo costume da comunidade como tipos de vestimenta, as saías longa não se viu mais, os costumes se perderam no tempo.

Os moradores e parentes próximos falaram sobre a vida dessas mulheres e a relevância das mesmas para a formação da comunidade, com isso percebe-se que essas mulheres faziam "serviço de homens" e gostavam das coisas feitas de forma correta, tinham gênio e atitude forte e tudo que elas falavam, estava falado, não votavam atrás de suas opiniões.

O papel das três mulheres para a formação da comunidade se deu através de espaço e convívio social, do seu jeito de viverem, da opinião forte, da força em encarar a vida e o trabalho, da organização das festas, dos costumes presentes na memória de todos.

Lembramos que os novos de hoje serão os velhos do amanhã e que os causos contatos cada dia ficam menos frequentes, a correria dos dias atuais tem nos impedido de compartilhar memórias, deixando de lado a memória através do seu tempo. 


\section{REFERÊNCIAS}

BARDIN, Laurence. Análise de conteúdo. Lisboa: Edições 70, 1979.

BITTERNCOOURTY, Circe Maria Fernandes. Ensino de história: fundamentos e métodos. 3.ed. São Paulo: Cortez, 2009.

BOSI, Ecléa. Memória e sociedade: lembranças dos Velhos. 3. ed. São Paulo: Companhia das Letras, 1994.

2003.

O tempo vivo na memória: ensaios de psicologia social. São Paulo: Ateliê Editorial,

JODELET, Denise. La representación social: fenómenos, concepto y teoría. In: MOSCOVICI, Serge (org). Psicologia Social. Barcelona: Paidos, 1985. p. 469-494.

Représentations sociales: un domain en expansion. In: __ (org.) Les Représentations Sociales. Paris: Presses Universitaires de France. 1989. pp. 31-61

LE GOFF, Jacques. História e memória. Tradução Bernardo Leitão... [et al.]. $7^{\circ}$ ed. Revista Campinas. São Paulo: Editora da Unicamp, 2013.

Historie et mémoire. Paris: Galimard, 1988.

MEIHY, José Carlos Sebe Bom; HOLANDA, Fabiola, História oral: como fazer, como pensar. São Paulo: Contexto, 2013.

MINAYO, Maria Cecília de Souza et. al. Pesquisa Social: teoria, Métodos e criatividades. Petrópolis, RJ: Vozes, 2016.

OLIVEIRA, Maria Marly de. Como fazer pesquisa qualitativa. 3. ed. Revista e ampliada. Petrópolis R.J: Vozes, 2010.

PERAZZO, Priscila F. Narrativas Orais de Histórias de Vida. Comunicação \& Inovação, PPGCOM/USCS v. 16, n. 30 (121-131) jan-abr 2015.

PINTO, Ana Lucia Guedes; GOMES, Geisa Genaro; SILVA, Leila Cristina Borges Da. Memórias de leitura e formação de professores. Campinas, São Paulo: Mercado das Letras.2008.

PROENÇA, Maria Cândida. Ensinar/aprender História: questões de didática aplicada. Lisboa: Livro Horizonte, 1990.

SANTOS, Milton. Metamorfose do espaço habitado. 2. ed. São Paulo: Hucitec, 1991. 